\title{
LA POLÍTICA DE AGUA Y SANEAMIENTO EN ARGENTINA: EL DESAFÍO DE LA UNIVERSALIZACIÓN DE LOS SERVICIOS
}

\section{WATER AND SANITATION POLICIES IN ARGENTINA: THE CHALLENGE OF UNIVERSALIZING SERVICES}

\section{Verónica L. Cáceres ${ }^{1}$}

\section{Resumen}

El presente artículo tiene como propósito central contribuir a la reflexión y al debate sobre la política de agua y saneamiento en Argentina. Para lo cual se presentan los aspectos normativos e institucionales que encuadran la gestión de los servicios en el país; se caracterizan las cinco etapas que la política ha transitado y que marcaron el devenir del sector; y por último, como conclusiones, se da cuenta de los principales desafíos que enfrenta el sector.

Palabras claves: Estado; Políticas Públicas; Servicios de Infraestructura; Acceso.

\begin{abstract}
This article is aimed at contributing to the reflection and debate on the water and sanitation policies in Argentina. For this purpose, regulatory and institutional aspects are discussed regarding services management in the country. The paper also includes a characterization of the five stages of such policies that have marked the progress of the sector. Finally, the main challenges faced by the sector are mentioned as a conclusion.
\end{abstract}

Keywords: State; Public Policies; Infrastructure services; Access.

doi: http://dx.doi.org/10.15359/evs.19-46.6

Fecha de recepción: 01-07-2014. Fechas de reenvíos: 19-07-14/23-12-2014/29-12-2014. Fecha de aceptación: 3012-14. Fecha de publicación: 31-12-14

${ }^{1}$ Profesora Universitaria en Economía. Magister en Ciencias Sociales. Doctoranda en Ciencias Sociales. Investigadora-Docente del Instituto del Desarrollo Humano, Área de economía, Universidad Nacional de General Sarmiento, Argentina. vcaceres@ungs.edu.ar

94

Verónica L. Cáceres

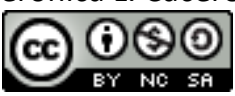

Artículo protegido por licencia Creative Commons 


\section{Introducción}

La política pública de agua y saneamiento refiere a un proceso de toma de posición, predominante, del Estado tendiente a ocuparse de la problemática de la prestación, operación, mantenimiento de las instalaciones, expansión y provisión transitoria mediante formas sustitutas a los no usuarios así como la regulación, control y fiscalización de los servicios. En las últimas décadas en el marco de la creciente contaminación, mercantilización y deterioro de los recursos hídricos adquirió mayor relevancia social y política.

Asimismo, la prestación de los servicios de agua y saneamiento conforman parte de los servicios públicos urbanos prestados, por sus características estructurales, bajo monopolios naturales. Dichos servicios constituyen espacios privilegiados para la acción estatal porque se vinculan a un derecho humano inalienable, conforman eslabones centrales para el desarrollo económico, posibilitan la integración territorial y generan fuertes externalidades positivas en lo que concierne a la salud, a las condiciones de vida de la población y del ambiente.

En la República Argentina estos servicios se conformaron en las últimas décadas del siglo XIX, como parte de las políticas sanitarias y de control de las epidemias de cólera y fiebre amarilla y se expandieron a partir de la intervención del Estado nacional durante las primeras décadas del siguiente siglo. Desde entonces, los servicios han sido tramitados mediante modelos de gestión pública centralizada o descentralizada, bajo gestión privada, y nuevamente, bajo gestión pública mediante distintos tipos de empresas.

El presente artículo tiene como propósito central contribuir al debate y a la reflexión sobre el devenir de la política de agua y saneamiento en Argentina, a partir de presentar una periodización de cada una de las etapas, que permita contextualizar los desafíos que enfrenta el sector transcurrido una década y media del siglo XXI. La estructura adoptada es la siguiente: en primer lugar, se presentan los aspectos normativos e institucionales que encuadran la gestión de los servicios en el país; en segundo, se caracterizan las cinco etapas que la política sectorial ha transitado; y por último, como conclusiones, se da cuenta de los principales desafíos que enfrenta el sector.

\section{Metodología}

El desarrollo de este trabajo recurrió, por un lado, a la observación documental de las memorias institucionales de la empresa nacional prestataria de los servicios de agua y saneamiento con injerencia hasta 1992, normativas y trabajos previos(entre las fuentes se encuentran: OSN (1966), OSN (1935), Aguas Argentinas (1999); entre las normativas Decreto del Poder Ejecutivo Nacional N. ${ }^{\circ} 1173$ N. ${ }^{\circ} 1173,2004$, Decreto del Poder Ejecutivo Nacional N. $214 \quad$ N. 214 (2002),

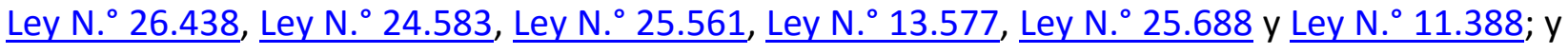

Verónica L. Cáceres

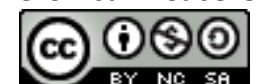

Artículo protegido por licencia Creative Commons 
entre los trabajos: Regalsky (ㅁ10), Rey (2003), Tartarini (2007), Azpiazu, Catenazzi \& Forcinito (2004). Por otro lado, desde el punto de vista cuantitativo, se analizaron los datos de los Censos Nacional de Población, Vivienda y Hogares.

En una primera aproximación se identificaron y relevaron los documentos y los datos de cobertura de los servicios de los Censos; luego se clasificó la información recogida, se delinearon las etapas de la política y se analizó la información.

\section{Resultados}

Aspectos normativos e institucionales de la política de agua y saneamiento

En la República Argentina, país que adopta la forma federal de gobierno, la responsabilidad sobre la provisión de los servicios públicos de agua y saneamiento recae sobre las jurisdicciones provinciales $y$, por delegación de estos últimos, en algunos casos también sobre ciertos municipios. Esto es así desde 1980, cuando el gobierno cívico-militar decidió descentralizar y transferir los servicios que se encontraran en la esfera de la empresa Obras Sanitarias de la Nación (en adelante OSN).

El esquema de organización federal adoptado reconoce la preexistencia de las provincias a la Nación, por ello los Estados provinciales conservan las competencias no delegadas por la Constitución al gobierno federal. Con la reforma constitucional de 1994 quedó claramente establecido que corresponde a la Nación la responsabilidad de "dictar las normas que contengan los presupuestos mínimos de protección" y a las provincias "el dominio originario de los recursos naturales existentes en su territorio" (Constitución Nacional de Argentina, s. f., artículos 41 y 124). Es decir, el agua, como el resto de los recursos naturales es propiedad de las provincias. Mientras, la Nación acuerda los Principios Mínimos en materia ambiental, lo cual le corresponde a las provincias complementarlos.

En tanto, los servicios están descentralizados y constitucionalmente las provincias tienen el dominio originario de sus recursos naturales, no existe una Ley Nacional del Agua que fije lineamientos de la política hídrica ni una política unificada de los servicios de agua y saneamiento en todo el territorio. La cual incentive el uso eficiente $y$ ambientalmente sostenible del recurso que reconozca el derecho al acceso de la presente generación y futura, de tal manera que provea seguridad jurídica en los derechos de uso y en la resolución de potenciales conflictos entre las jurisdicciones, empresas y usuarios y considere los problemas de equidad social y de distribución territorial del recurso. 
En cambio, se observa un conjunto de normativas que regulan de forma directa o indirecta distintas aristas de los recursos hídricos, entre las que se encuentra la Ley N. 25.688 de 2002 denominada Régimen de Gestión Ambiental de Aguas que legisla en materia de cuencas interjurisdiccionales y crea los comités de cuencas como organismos federales de asesoramiento. Cabe destacar que la misma aún no ha logrado los consensos con las provincias que han considerado que la norma avanza sobre competencias no delegadas a la Nación, por ello, el Poder Ejecutivo Nacional (PEN) todavía no la ha reglamentado (Picolotti, 2003).

Asimismo, en 2003, se firmó el Acuerdo Federal del Agua y los Principios Rectores de Política Hídrica por parte de la Nación, las provincias y la Ciudad Autónoma de Buenos Aires (en adelante (ABA). En un marco de federalismo concertado se intentó avanzar en las bases de una política hídrica nacional con la inclusión de distintos sectores y de los aspectos sociales, económicos y ambientales y de los principios de protección del recurso. Más allá de lo cual desde 2005 espera ser tratado en el parlamento nacional el Proyecto de Ley Marco de Política Hídrica que retoma los principios del acuerdo que aún no tienen rango de ley. En diciembre de 2008 se sancionó la Ley N.² 26.438 que solo ratificó el Acta Acuerdo, la Carta orgánica, las Actas con modificaciones convenidas y que reconoció al Consejo Hídrico Federal (COHIFE) como instancia federal para la concertación y coordinación de la política hídrica federal.

Finalmente, al entramado de normativas nacionales se agregan las formuladas por cada una de las jurisdicciones provinciales que incluyen, fundamentalmente, el establecimiento de los Códigos de Agua y los marcos regulatorios de la provisión de los servicios.

Contrariamente a lo que sucede en países como Uruguay, Ecuador y Bolivia en el país no hay un reconocimiento explícito del derecho humano al agua y saneamiento en la carta magna, más allá de lo cual al adherir en 1986, bajo la presidencia de Raúl Alfonsín al Pacto Internacional de Derechos Económicos, Sociales y Culturales (PIDESC), el Estado argentino está obligado a asumir las responsabilidades que el pacto y su protocolo, ratificado en 2011, le confieren.

En 2002, el comité responsable de supervisar el cumplimiento del PIDESC formuló la Observación General N. 15 que reconoció el acceso al agua y saneamiento como derechos humanos, incluidos dentro de los articulados del PIDESC. Cabe destacar, que en el país, a partir de dichas normativas, el poder judicial sentó jurisprudencia con respecto a estos derechos y las responsabilidades que le competen al Estado nacional y a los estados subnacionales.

Por último, desde la descentralización de los servicios cada jurisdicción provincial adoptó su propio modelo de prestación y el Estado nacional mantiene solo bajo su órbita la prestación en una porción del territorio comprendido por la CABA y 17 municipios del Conurbano bonaerense. 


\section{Etapas de la política de agua y saneamiento en Argentina}

A continuación, presentamos una caracterización de las etapas que atravesó la política de agua y saneamiento en Argentina: una primera fase que coincide con la consolidación del modelo agroexportador (1869-1930) ${ }^{2}$, una segunda caracterizada por el crecimiento de la población en la periferia de la CABA en el marco de la Industrialización por Sustitución de Importaciones (ISI) (1930-1976); una tercera de promoción, concreción y desarticulación de los servicios con la descentralización durante el gobierno cívico-militar y el retorno de la democracia (1976-1991); una cuarta de privatizaciones durante el auge del modelo neoliberal (1991-2006) y por último la más reciente de reestatizaciones en el contexto de salida de la mayor crisis política, social y económica del país (2006-2014) ${ }^{3}$.

\section{Agua y saneamiento durante el modelo agroexportador}

Cabe destacar que el servicio de agua fue inaugurado bajo el gobierno de Domingo Faustino Sarmiento, en 1869, para abastecer inicialmente a una parte de la actual CABA. Los orígenes se vinculan directamente con la crisis sanitaria desatada por las epidemias de cólera de 1867 y de fiebre amarilla en 1871 que azotaron a la ciudad y se vieron influenciados por el pensamiento higienista.

El desarrollo de la infraestructura se efectuó en el marco de la inserción del país en el mercado internacional, como productor de materias primas, fundamentalmente de carnes, cueros y granos, durante el modelo agroexportador. Esta situación repercutió en el crecimiento de la población de la CABA que presentaba una actividad portuaria relevante y se constituía como sede del gobierno nacional y provincial, pero al mismo tiempo advertía notables problemas de salubridad, producto de las precarias condiciones de provisión de agua y resolución del saneamiento doméstico y de la incipiente actividad industrial.

\footnotetext{
${ }^{2}$ El desarrollo económico se entiende como "el proceso de transformación de la economía y la sociedad fundado en la acumulación de capital, conocimientos, tecnología, capacidad de gestión y organización de recursos, educación y capacidades de fuerza de trabajo, y de sostenibilidad y permeabilidad de las instituciones, dentro de las cuales, la sociedad transa sus conflictos y moviliza su potencial de recursos" (Ferrer, 2009). La economía argentina ha transitado las siguientes etapas: la economía primaria-exportadora (1860-1930), la industrialización sustitutiva de importaciones (1930-1975); la hegemonía financiera (1976-2001), y la que inicia en 2002-2003 y continúa vigente denominada por algunos autores como neodesarrollista, de recuperación, etc.

${ }^{3}$ En 1998 la economía argentina quedó inmersa en una profunda recesión con una importante contracción del nivel de actividad y elevados niveles de desempleo y pobreza, en 2001 estalló en una crisis de niveles inéditos tras la salida de activos financieros del país. En enero de 2002 el gobierno provisional de Eduardo Duhalde, tras la sanción de la Ley de Emergencia Pública y Reforma del Régimen Cambiario N. ${ }^{\circ} 25.561$, dio por finalizada la convertibilidad de la moneda argentina respecto al dólar estadounidense, que desde 1991 sostenía que $\$ 1=$ US\$ 1. Posteriormente, el tipo de cambio se mantuvo, hasta fines de 2011, en $\$ 4=$ US\$ 1 (con fluctuaciones) y en diciembre de 2012 finalizó \$4,82= US\$1.
}

98

Verónica L. Cáceres

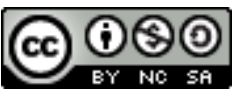

Artículo protegido por licencia Creative Commons 
Laurelli (1988) sostiene que el desarrollo de los servicios en la CABA se vinculó con la concurrencia de dos circunstancias, por un lado, "el asentamiento de la oligarquía pampeana, de grupos financieros, comerciantes y prestadores de servicios no escapó el proceso de modernización desencadenado por este grupo de vecinos frente al modelo europeo, y por otro, el azote de epidemias que desde el siglo XIX castigaban sin respetar jerarquías sociales". Cabe destacar que cuando se inició el servicio de agua, la CABA se encontraba bajo jurisdicción de la provincia de Buenos Aires (PBA). Si bien el servicio dependía inicialmente de la Dirección del Ferrocarril del Oeste, en 1870, quedó a cargo de la Comisión de Obras de Salubridad encargada de realizar los estudios para la expansión de los servicios.

A partir de la desvinculación política de la CABA de la PBA, tras la federalización y su puesta en jurisdicción nacional, en 1880, durante el gobierno de Nicolás Avellaneda, el Estado nacional pasó a intervenir directamente en la provisión al colocar a la Comisión en el ámbito del Ministerio del Interior, organismo centralizado. En ese contexto, el desarrollo de las obras encontró como condicionante central la escasez de recursos financieros y en 1887 el gobierno decidió concesionar a capitales privados, particularmente a la empresa Buenos Aires Water Supply la terminación y posterior explotación de las obras.

La gestión privada se vio condicionada por los problemas financieros ligados a la crisis en los mercados centrales, la imposibilidad de colocar bonos tendientes a financiar las obras, el quiebre de la entidad financiera involucrada y la inviabilidad de las tarifas depreciadas (Regalsky, 2010). Por lo que, los servicios retornaron en 1892 a la prestación a cargo del Estado nacional en el ámbito del Ministerio del Interior.

En este marco, también hacia 1890, a fines del gobierno de Miguel Juárez Celman, el Estado Nacional comenzó a ser demandado por las jurisdicciones del interior del país para apoyar o iniciar las obras de agua y saneamiento (ya que hasta entonces solo se ocupaba de los servicios en la CABA). Regalsky (2010) sostiene que seguidamente el Estado apuntó lo siguiente: a) a otorgar un conjunto de subvenciones a los gobiernos locales para la implementación de los programas; b) a construir obras con recursos del Tesoro Nacional; c) a supervisar y brindar apoyo técnico a los miembros de la Comisión.

Para 1898, durante el gobierno de Julio Roca, el Estado nacional consolidó un dispositivo normativo (e institucional) que le permitió intervenir en el sector en todo el país y lo hizo a partir de la creación del Ministerio de Obras Públicas y la transformación de la Comisión de Salubridad en la Dirección General de Obras de Salubridad (DGOS). Así se pasó de una institución ocupada de la gestión del agua y saneamiento de la CABA a otra de alcance nacional. 
En 1900, el legislativo aprobó el inicio de las obras sanitarias en diez capitales de las provincias argentinas -Santa Fe, Córdoba, Mendoza, Salta, Jujuy, Catamarca, La Rioja, Santiago del Estero, San Luis, Tucumán- y dispuso que se afectará la mitad de los recursos correspondientes a las provincias provenientes de la lotería nacional para la financiación de las obras.

La expansión de los servicios durante las primeras décadas del siglo XX continuó con base en un esquema tarifario que tuvo como elemento central un sistema de subsidios cruzados entre tipos de usuarios (residenciales y no residenciales), zonas geográficas con distinta densidad de población, distancia relativa de las tomas de agua y distinto desarrollo económico relativo; y mediante un esquema en el servicio de agua no medido; y con recursos provenientes del Tesoro Nacional.

Para algunos autores la política en esta etapa se caracterizó inicialmente por "la prestación estatal y universal" que conformó "un elemento clave en determinado momento de la formación del Estado Nación que asoció la garantía del acceso de determinados servicios al hecho de ser ciudadano, y que representaba sobre todo el valor de un programa político más allá de su efectiva prestación" (Catenazzi, 2004). Con Laurelli se coincide (1988) bajo esta mirada "los servicios debían extenderse a todos los grupos sociales".

En 1912, en un contexto signado por el crecimiento de la población en la CABA, el Estado nacional convirtió a la DGOS en un ente autárquico denominado OSN. Cabe destacar que por fuera del sistema de OSN se fue institucionalizando los esquemas de provisión administrados por la PBA, por empresas privadas y algunos municipios. Aunque en 1926 se sancionó la Ley N. ${ }^{\circ}$ 11.388 que permitió la formación de nuevas cooperativas, el sistema no cobró relevancia "para estos servicios monopolizados por el Estado en la figura de OSN" (Laurelli, 1988).

\section{Crecimiento de la población en el Conurbano bonaerense}

En el marco de la crisis de los años treinta, la economía argentina sufrió una contracción de la producción, del ingreso y del empleo y un fuerte desequilibrio en los pagos internacionales, en tanto la caída de las exportaciones dificultaba sostener el precio de las importaciones, el pago de los servicios de la deuda y la transferencia de utilidades de las empresas extranjeras radicadas en el país (Ferrer, 2008). Esta situación motivó el abandono de las políticas librecambistas por parte del régimen político de signo conservador que gobernaba el país para conformarse un esquema regulatorio de los principales mercados (producción de cereales, control del cambio, etc.). Lo cual dio paso a una "drástica ampliación de la presencia del Estado", Ferrer (2008), y a un proceso de ISI que resultó, en sus inicios, la alternativa posible para enfrentar los efectos de la crisis que, asimismo, obtuvo respaldo en la región. En el caso argentino, el Estado nacional ocupó un rol central, tanto en las transferencias de ingresos hacia el sector industrial a través de subsidios, créditos promocionales, como en su rol de regulador de conflictos sociales y arbitro de las pujas 100

Verónica L. Cáceres

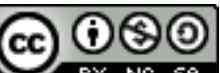

Artículo protegido por licencia Creative Commons 
redistributivas (Kosacoff, 1988). Con respecto a OSN, su funcionamiento no estuvo desligado de lo que sucedía en el plano político y económico nacional y tras la crisis debió sustituir productos importados.

Cabe destacar que con la intensificación de la producción de manufacturas y la instalación de industrias en los municipios que integraban el primer cordón del Conurbano bonaerense en la PBA, fundamentalmente Avellaneda, Lanús, San Martín y Quilmes se produjo un flujo migratorio del interior del país y el asentamiento de trabajadores urbanos de menores ingresos que comenzaron a acceder al suelo sin infraestructura en el segundo cordón mediante un proceso de suburbanización, en el marco de los loteos económicos y abaratamiento del transporte en conjunto con un proceso de autoconstrucción (Torres, 1993).

Mientras en el interior del país, OSN apuntó a ampliar las obras para las pequeñas localidades, efectuar subvenciones de partidas mediante el "Plan de trabajos públicos"; realizar empréstitos sin plazo fijo con cargo de devolución mediante los bonos de salubridad e imponer "la uniformidad tarifaria con Capital Federal" (Laurelli, 1988). En relación con el Conurbano, OSN creó el Distrito Sanitario Aglomerado Bonaerense con el objetivo de institucionalizar la unidad técnicoadministrativa a partir de la firma de distintos convenios entre la PBA y el Estado nacional que permitieron incorporar a los municipios del Conurbano a OSN, bajo la Ley Orgánica N. ${ }^{\circ} 13.577$.

El plan aunque contaba con los instrumentos legales, un conjunto de obras programadas en el tiempo y las fuentes de financiamiento nunca fue aprobado. Más allá de lo cual, como sostiene Brunstein (1988) se intentó "aprovechar" partes del programa que terminaron "siendo desvirtuadas", en tanto estuvo formulado para atender el Gran Buenos Aires y terminó adaptado para todo el país.

En líneas generales, tanto en el Conurbano como en el interior, las acciones emprendidas por OSN pueden resumirse de la siguiente manera: a) la promoción de la expansión de redes de distribución y el número de conexiones en detrimento de una reestructuración de obras básicas que atendieran a la producción de agua o tratamiento de líquidos cloacales; b) el financiamiento a largo plazo de las instalaciones; c) la ampliación de los servicios en el interior mediante la construcción y operación de los "servicios reducidos" (fuentes gratuitas y sin redes de distribución en pequeñas localidades); d) la promoción de la prestación de los servicios, con exclusividad de OSN, al permitir acogerse a los distintos niveles jurídicos, provinciales y municipales a la Ley Orgánica de OSN (Laurelli, 1988).

En este marco, en las décadas del cincuenta y sesenta del Siglo XX, y según Brunstein (1988) la expansión de los servicios "no acompañó al crecimiento de la demanda" ya que, por un lado se privó del acceso a los hogares que se incorporaban dentro del área bajo jurisdicción de OSN y, 
por otro, al no ampliarse el área de prestación, los hogares que pasaron a autoconstruir sus viviendas en el segundo cordón del Conurbano lo hicieron en municipios en que los que OSN no tenía jurisdicción. Esta situación se desplegó en la medida que, con el proceso de nacionalización de distintas empresas, acaecida durante el peronismo, el Estado nacional pasó a ser responsable de la producción de otros servicios.

De esta manera, se redujeron las inversiones destinadas, fundamentalmente, a obras que permitieran el mantenimiento de las infraestructuras preexistentes y posibilitaran la ampliación y construcción de nuevas plantas de potabilización del agua y de tratamiento de los efluentes, situación que impactó posteriormente en la reducción de las conexiones. Dicha situación de acuerdo con Catenazzi (2004) dejó lugar "a nuevos rasgos de intervención estatal en función de los cuales comenzó a plantearse el racionamiento del consumo" y reducirse la realización de obras básicas de producción "congelando los perímetros servidos". En este marco, como plantea la autora, se rompió cierto "...equilibrio entre el crecimiento de la ciudad y la producción y consumo del servicio de red, contribuyendo a una diferenciación socio espacial acentuada por los diferentes grados de equidad en el acceso al servicio".

Asimismo, cabe señalar que el crecimiento de la población en áreas sin los servicios, especialmente en el Conurbano, fue posibilitada por la presencia de formas sustitutas de acceso derivadas de la extracción de agua subterránea mediante perforaciones domésticas, el depósito de efluentes en los suelos mediante pozos y la presencia de circuitos mercantiles, con pequeñas empresas dedicadas a la comercialización de los servicios de construcción de las instalaciones y de sus insumos.

La figura 1 muestra cómo se modificó la población con acceso a agua y cloacas por redes en Argentina.

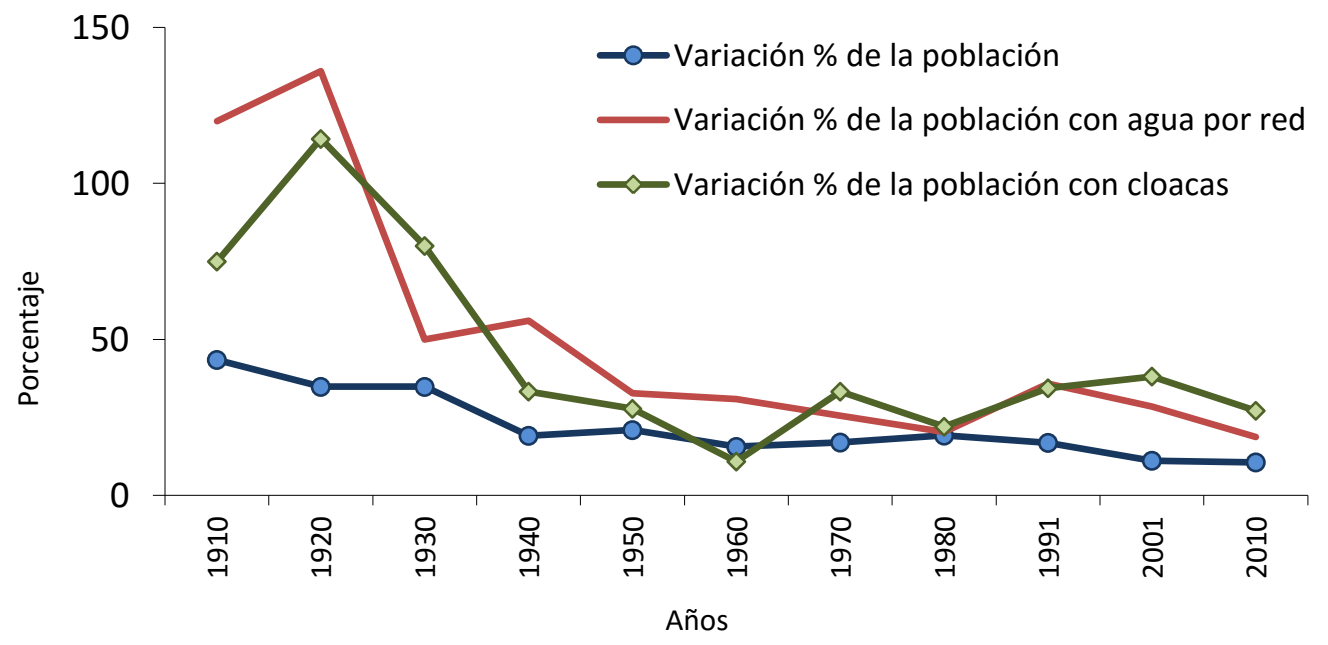

Figura 1. Variación porcentual de la población total y la conectada a los servicios de agua y cloacas. Fuente: elaboración propia con base en los datos del INDEC (2011).

102

Verónica L. Cáceres

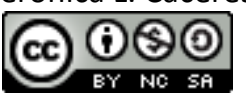

Artículo protegido por licencia Creative Commons 
La descentralización y desarticulación del sector

Las profundas transformaciones que experimentó el sector de agua y saneamiento formaron parte de las acciones emprendidas por el gobierno cívico-militar de Jorge Rafael Videla que fueron en línea con el desmontaje de la faceta empresaria del Estado y de la industrialización por sustitución de importaciones tendiente a reducir el poder de los sindicatos y avanzar en el disciplinamiento de la clase trabajadora.

La descentralización en el sector se intentó implementar, inicialmente en la década del sesenta, pero fue resistida por las provincias y logró ser impuesta a fines de 1979. Esta decisión fue impulsada por los condicionamientos políticos emanados del Fondo Monetario Internacional (FMI) y el Banco Mundial (BM) (Ordoque Urcelay, 2007) e incluyó al personal de OSN, los activos libres de pasivos de la empresa y los usuarios.

Cada provincia conformó su propio modelo de gestión que incluyó la prestación directa mediante empresas públicas o direcciones provinciales, la transferencia a las jurisdicciones municipales y/o la conformación de cooperativas. Cabe destacar que el Estado nacional mantuvo bajo su jurisdicción la prestación, únicamente, de los servicios en la CABA y en trece municipios del Conurbano. Situación que se justificó por el "carácter técnicamente indivisible" del sistema de mallas de redes que conectaba los sistemas de potabilización, conducción y distribución de agua potable, y parcialmente, el sistema de recolección y disposición de los desagües cloacales de la CABA y los municipios del Conurbano (Schifini, 1998). Aunque existieron algunos intentos de transferir el territorio, estos no prosperaron.

Para cuando los servicios fueron transferidos solo el 57,34 \% de la población del país accedía al servicio de agua y el $30 \%$ al de cloacas, por lo que el sistema desproveía, en términos absolutos, a 11.900.000 de personas del servicio de agua y 19.000 .000 del servicio de cloacas (INDEC, 1981).

Del modelo de provisión de agua y saneamiento centralizado en OSN, la descentralización dio lugar, a inicios de 1982, al surgimiento de más de un centenar de sistemas de provisión, entre las que se encuentran: la emergencia de empresas provinciales como la Administración de Obras Sanitarias Corrientes y la Administración General de Aguas de Salta; prestaciones municipales en la Provincia de Entre Ríos y concesiones a cooperativas en Chubut.

El Estado nacional delegó a las provincias el gasto de la provisión de los servicios, pero no estableció el financiamiento de las obras necesarias para sostener y universalizar los servicios (y la expansión quedó limitada por la redistribución regresiva del ingreso en cada una de las jurisdicciones).

Las provincias se vieron condicionadas también por la falta de experiencia en la planificación y gestión de los servicios y de recursos humanos especializados. 
De esta forma, la descentralización se concibió como paso previo a la privatización de las empresas, objetivo del equipo económico liderado por José Alfredo Martínez de Hoz que, previamente avanzó en un proceso de privatización periférica con la privatización parcial de algunas actividades desarrolladas por otras empresas públicas e impulsó la descentralización en aquellas que, por su tamaño relativo, no resultara viable la privatización. Según Brunstein (1988) esto "no fue más que la búsqueda de deshacerse del sistema y nada tuvo que ver con la consideración de los intereses sociales".

Aunque el gobierno cívico-militar no avanzó en la privatización de OSN, la modalidad que asumió el proceso y las distintas restricciones obligaría en la práctica a privatizar las principales empresas más adelante (Azpiazu y Forcinito, 2004).

En la década del ochenta, el legado que heredó el gobierno democrático del Raúl Alfonsín, incluía la atomización del sector y una merma en las inversiones. En términos del entramado institucional sectorial, mientras el Estado nacional mantuvo un rol relevante en una parte pequeña del territorio procuró reservarse "un papel de coordinación y garantía de los objetivos a largo plazo" del sector (Brunstein, 1988) al transformar el Servicio Nacional de Agua Potable (SNAP) en el Consejo Federal de Agua Potable y Saneamiento (COFARyS) que funcionó en órbita de la Secretaría de Recursos Hídricos del Ministerio de Obras y Servicios Públicos.

En términos de los programas implementados por OSN se destaca el PROAGUA que dependió directamente de la Presidencia de la Nación mediante su Secretaria General y que estuvo destinado a proveer agua potable en asentamientos marginados de zonas urbanas, especialmente en "villas miserias". Brunstein (1988) explica que el programa contó con tres modalidades básicas de acción: I) extensión de las redes cuando los asentamientos se encontraran junto a un área abastecida y con capacidad sobrante; II) realizar perforaciones in situ cuando lo primero no fuese posible y los recursos subterráneos lo permiten; y III) transportan agua en camiones cisterna cuando las anteriores alternativas no sean posibles.

En líneas generales, el fracaso de la política económica del gobierno de Alfonsín, sumado al legado que recibió, puso en jaque y postergó el desarrollo de otros programas de expansión de los servicios, hecho que actuó como caldo de cultivo para que ya, durante la década del noventa, se promocionaran y concretaran las privatizaciones de las principales empresas. Para entonces, la fuerte desinversión del sector constituía un reflejo de más de dos décadas en que la problemática del acceso seguro al agua y saneamiento no conformaba una cuestión socialmente problematizada en la agenda pública. 


\section{Las privatizaciones}

Durante la década del noventa del siglo pasado, las privatizaciones fueron promovidas en la sociedad argentina como el único camino para universalizar los servicios y atender a la población no abastecida, así como mejorar la calidad de la prestación y los niveles de micromedición del consumo de agua. Si bien técnicamente los bienes y la infraestructura de las empresas prestatarias no fueron vendidas o, por lo que el Estado nacional o subnacional otorgó los derechos para operar los activos a cambio de distintas obligaciones, en la práctica, entendemos "que el usufructo del derecho de explotación de una empresa de propiedad estatal por parte de una privada por un periodo de tiempo constituye una forma de privatización, y no simplemente un modo de participación del capital privado en la actividad, en la medida en que involucra una transformación radical en la lógica de funcionamiento de la firma cuyo fin principal pasa a ser la maximización de la tasa de ganancia y la utilización de la misma en función de los imperativos que plantea la reproducción ampliada del capital" (Azpiazu \& Forcinito, 2004).

Cabe destacar que, en 1991, en Argentina la cobertura del servicio de agua exhibía una profunda demanda insatisfecha, ya que alcanzaba solo al $66,6 \%$ de la población y la cobertura se reducía notoriamente en el caso de las cloacas para llegar al 34,2 \% (INDEC, 1991). Por consiguiente, los niveles de micromedición eran paupérrimos y la falta de inversiones, en líneas generales, dificultaba la prestación eficiente de los servicios.

En este marco, la Provincia de Corrientes (donde la cobertura del servicio de agua alcanzaba al $65,9 \%$ de la población) se convirtió en pionera al llevar adelante la privatización de los servicios prestados hasta entonces por la Administración de Obras Sanitarias de la Provincia de Corrientes. Luego, en 1993, Azpiazu \& Forcinito (2004), el Estado nacional privatizó de forma integral lo que quedaba de OSN, la cual pasó a manos del consorcio Aguas Argentinas S.A. que presentó en la licitación el mayor descuento en la tarifa base con respecto a la vigente. Posteriormente, la experiencia se propagó y repitió de forma acelerada en otras jurisdicciones subnacionales (provincias y municipios) los cuales optaron mayormente por la modalidad de concesión integral de los servicios por un periodo determinado (30 años) y con formas distintas de adjudicación a los interesados que incluyeron: el pago de un canon, la reducción en las tarifas vigentes, etc. Aunque, también se incorporó la participación privada mediante contratos de gestión y operación y transferencia (BM, 1996).

Las privatizaciones continuaron de la siguiente manera: en 1995, Formosa (con una cobertura que abastecía del servicio de agua solo al 55,1 \% de la población y 31,3\% en el caso de las cloacas); Tucumán (con una cobertura de 78,6 \% y 32,6 \%); Santa Fe (con una cobertura de 66,8\% y 27,4 \%); en 1997, afectaron a Santiago del Estero (con una cobertura de 53,8 \% y 13,8\%); Córdoba (que solo concesionó el servicio de agua cuya cobertura alcanzaba al 71,5 \% de la población); en 1998 
Mendoza (con una cobertura de $82,4 \%$ y $37,3 \%$ ); Salta (cuya cobertura alcanzaba al 83,2 \% y 42,3 $\%$ ); y en la última fase incluyó en 1999, la Provincia de Misiones (cuya cobertura alcanzaba al 41,7 \% y $7,1 \%$ ) y Buenos Aires (cuya cobertura variaba según los municipios afectados al proceso); en 2000 Catamarca (con una cobertura del $81 \%$ y 21,6 \%) y en 2002, La Rioja (cuya cobertura cubría al $83 \%$ y $21,7 \%$ ).La figura 2 muestra la evolución de la población con acceso al agua y al saneamiento por redes en Argentina desde inicios del siglo XX.

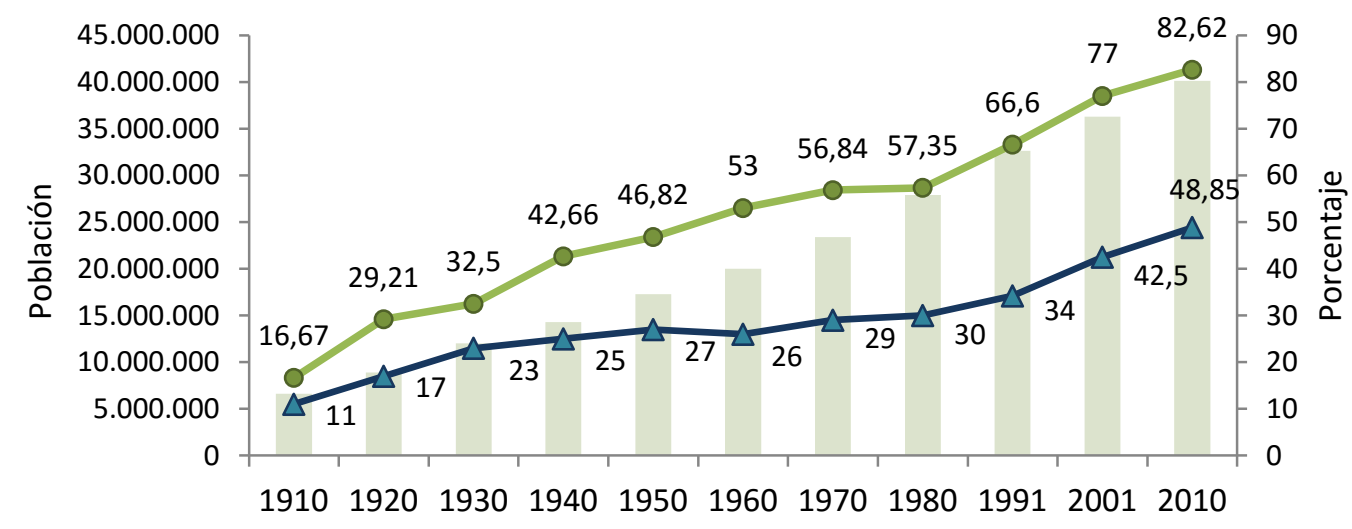

Población total - - $\%$ Población con agua por red $\longleftarrow$ Población con cloacas

Figura 2. Evolución de la población total y del porcentaje con agua y cloacas en Argentina. Fuente: elaboración propia con base en los datos publicados por el INDEC (2011).

Las privatizaciones incluyeron la separación de las funciones de prestación, que quedaron a cargo de actores privados, de las de regulación y control bajo responsabilidad del Estado nacional o provincial, situación que dio paso a la creación de agencias regulatorias y el establecimiento de marcos regulatorios que consideraron las condiciones de prestación de los servicios (calidad, tarifas, etc.).

Si bien desde la perspectiva económica dominante, la consideración del agua como una simple mercancía, subyacente en la política de privatizaciones, favorecería su aprovechamiento eficiente y equitativo, así como su protección y conservación, en la experiencia de Argentina, dichos resultados estuvieron lejos de alcanzarse en la mayor parte de los casos, los cuales se expandieron solo en las áreas más rentables. Contrariamente, las experiencias generaron profundos conflictos sociales, por ejemplo en Tucumán durante 1996-1997 y en Bahía Blanca en 2002 que incluyeron el rechazo de la población a los incrementos de las tarifas, a los cortes de los servicios, el retiro de los medidores, etc. 
En el marco de las reformas en el sector, cabe destacar que en 1995, mediante la Ley $\mathrm{N}^{\circ}$ 24.583, se disolvió el CoFAPyS y se creó el Ente Nacional de Obras Hídricas de Saneamiento (ENOHSA) como organismo descentralizado del Estado nacional que asumió sus funciones y continuó con una serie de programas que se encontraban en ejecución financiados por el Banco Internacional de Reconstrucción y Fomento (BIRF) y otros organismos otorgados fundamentalmente a cambio de que las provincias implementaran la privatización en el sector.

Para inicios del siglo XXI, en el marco de la mayor crisis política, institucional, social y económica que incluyó importantes movilizaciones de distintos sectores de la sociedad que reclamaban cambios institucionales profundos y en las orientaciones de las intervenciones del Estado, la renuncia de las autoridades (inclusive del Poder Ejecutivo Nacional), la sucesión de varios presidentes provisionales, la declaración unilateral del cese de pago de la deuda externa sumado a una compleja situación social con niveles de desempleo masivo, crecimiento de la pobreza e indigencia. La sanción de la Ley de Emergencia Económica y Reforma del Régimen Cambiario $\mathrm{N} .^{\circ} 25.561$ modificó el escenario en el que se habían desempeñado las operadoras de los servicios y tras la pesificación de la economía local, la depreciación de la moneda producto de la devaluación y la reafirmación de la prohibición de indexar las tarifas se observó una notable salida de los prestadores privados ${ }^{4}$.

En líneas generales, los trabajos relevados sostienen que el comportamiento de las empresas privatizadas en el sector de agua y saneamiento impactó de forma negativa en los hogares de menores ingresos y en las regiones del país menos favorables, tanto en lo que concierne al gasto destinado al consumo de los servicios como a la falta de obras de expansión, ya que las inversiones fueron menores a las comprometidas y se efectuaron -mayormente- en los sectores más rentables (Azpiazu y Bonofiglio, 2006, Azpiazu, Bonofiglio y Nahón,2008, entre otros) ${ }^{5}$.

\section{Proceso de reestatizaciones}

En Argentina, la intervención del Estado nacional y de los Estados provinciales en el sector tras la salida de la convertibilidad ha tenido matices que incluyeron la rescisión de los contratos y la

\footnotetext{
${ }^{4}$ En materia de prestación de servicios públicos se pesificó y desindexó las tarifas locales, lo que impidió que su costo acompañara los vaivenes del valor internacional del dólar e inició una etapa de renegociación de los contratos con las empresas privatizadas (incluyendo las de agua y saneamiento). El Decreto del Poder Ejecutivo Nacional N. ${ }^{\circ} 214$ (2002), firmado por el Poder Ejecutivo Nacional, incluyó la conversión compulsiva a pesos a las obligaciones de todo tipo expresadas tanto en dólares estadounidenses como en otras monedas extranjeras.

${ }^{5}$ Cabe destacar que la evaluación global del desempeño económico y social de las privatizaciones en Argentina se encuentra atravesada por diferentes posturas donde se destacan interpretaciones más positivas realizadas por teóricos y técnicos comprometidos con la implementación y otras más críticas. Sin embargo en el sector son pocos los trabajos que sitúan la mirada en el conjunto de casos y estos coinciden en que el desempeño no logró alcanzar los objetivos sociales propuestos vinculados a la universalización y mejora de la calidad.
} 
creación de nuevas empresas; el reordenamiento institucional de los entes de regulación y control y la sanción de nuevos marcos regulatorios. Asimismo, con respecto al entramado de gestión a nivel nacional, el ENOHSA pasó a ocupar un papel más activo en el sector a partir de la posibilidad de contratar y ejecutar obras, proyectos, adquirir materiales, maquinarias, y elementos destinados a la construcción, mantenimiento, operación y reposición de infraestructura (Decreto del Poder Ejecutivo Nacional N. ${ }^{\circ} 1173 \quad N^{\circ}{ }^{\circ} 1173,2004$ ).

En materia de provisión, si bien continuaron coexistiendo múltiples prestatarias de los servicios, con una heterogeneidad de formas de gestión, se observa en cada jurisdicción la presencia de un prestador principal en las ciudades principales y empresas de menor tamaño relativo (fundamentalmente en áreas periféricas de las grandes ciudades o en áreas rurales). Asimismo, se mantienen en la mayoría de los casos, los entes de regulación y/o de control, creados para la fiscalización de la prestación en manos de capitales privados, con tenues modificaciones en sus funciones. En las tablas 1 a 6 del apéndice se presentan las prestatarias de mayor tamaño de cada una de las jurisdicciones y los entes de regulación agrupados por regiones geográficas.

En tanto a fines de la década del noventa el grueso de las prestatarias de los servicios se encontraba concesionado a capitales privados, en 2010 la tendencia se revirtió con predominio de empresas con participación mayoritariamente estatal, como permite observar la figura 3.

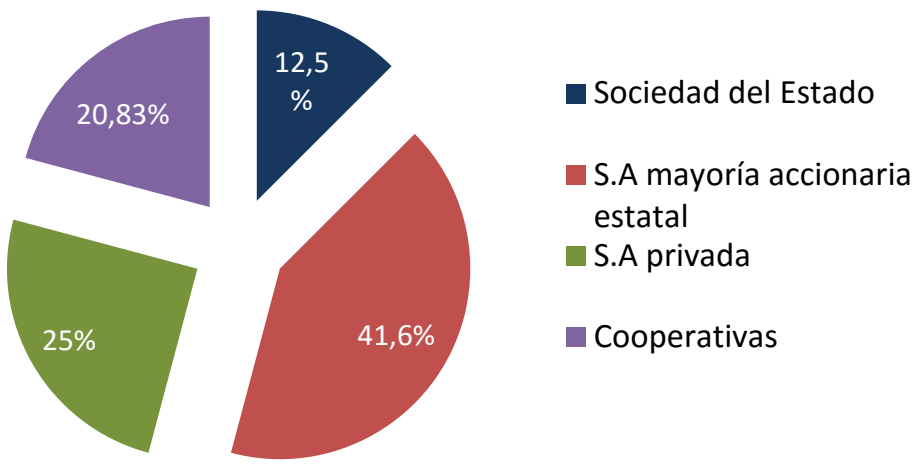

Figura 3.Prestatarias de los servicios de agua y saneamiento en la Argentina según forma jurídica. Fuente: elaboración propia con base en Saravia (2010).

En lo que concierne a la cobertura, mientras que en el 2001: el 77 \% de la población accedía al agua y al 42,5\% en el caso de las cloacas, en el 2010 alcanzaba al 82,6 \% y 48,8 \% de la población respectivamente. La cobertura en cada una de las jurisdicciones era heterogénea como permiten observar las figuras $\underline{4}$ y $\underline{5}$. 


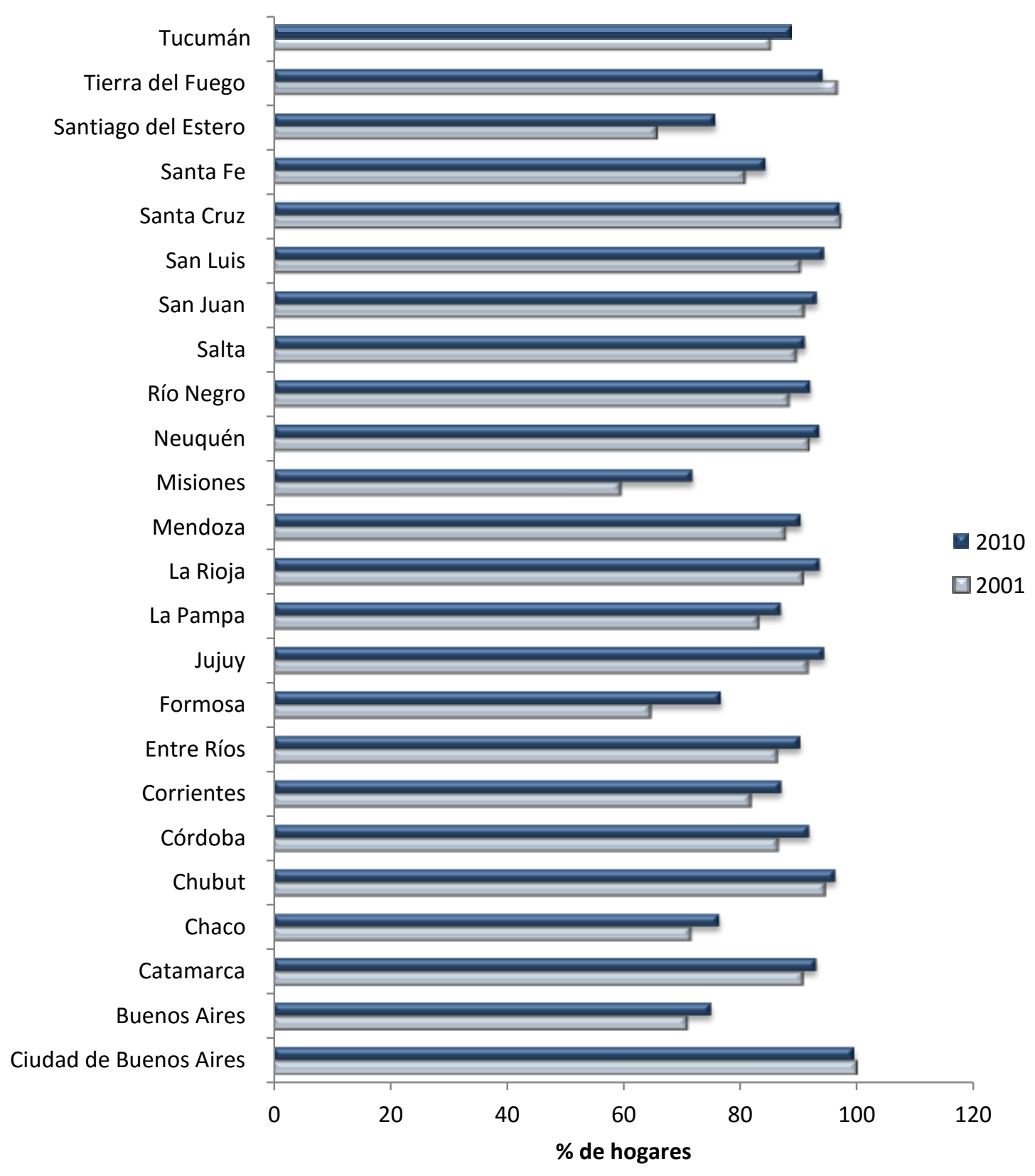

Figura 4. Cobertura de hogares con servicio de agua en Argentina (por jurisdicciones) (2001-2010). Fuente: elaboración propia, Azpiazu \& Forcinito (2004), con base en los datos del INDEC (2001 y 2010) 


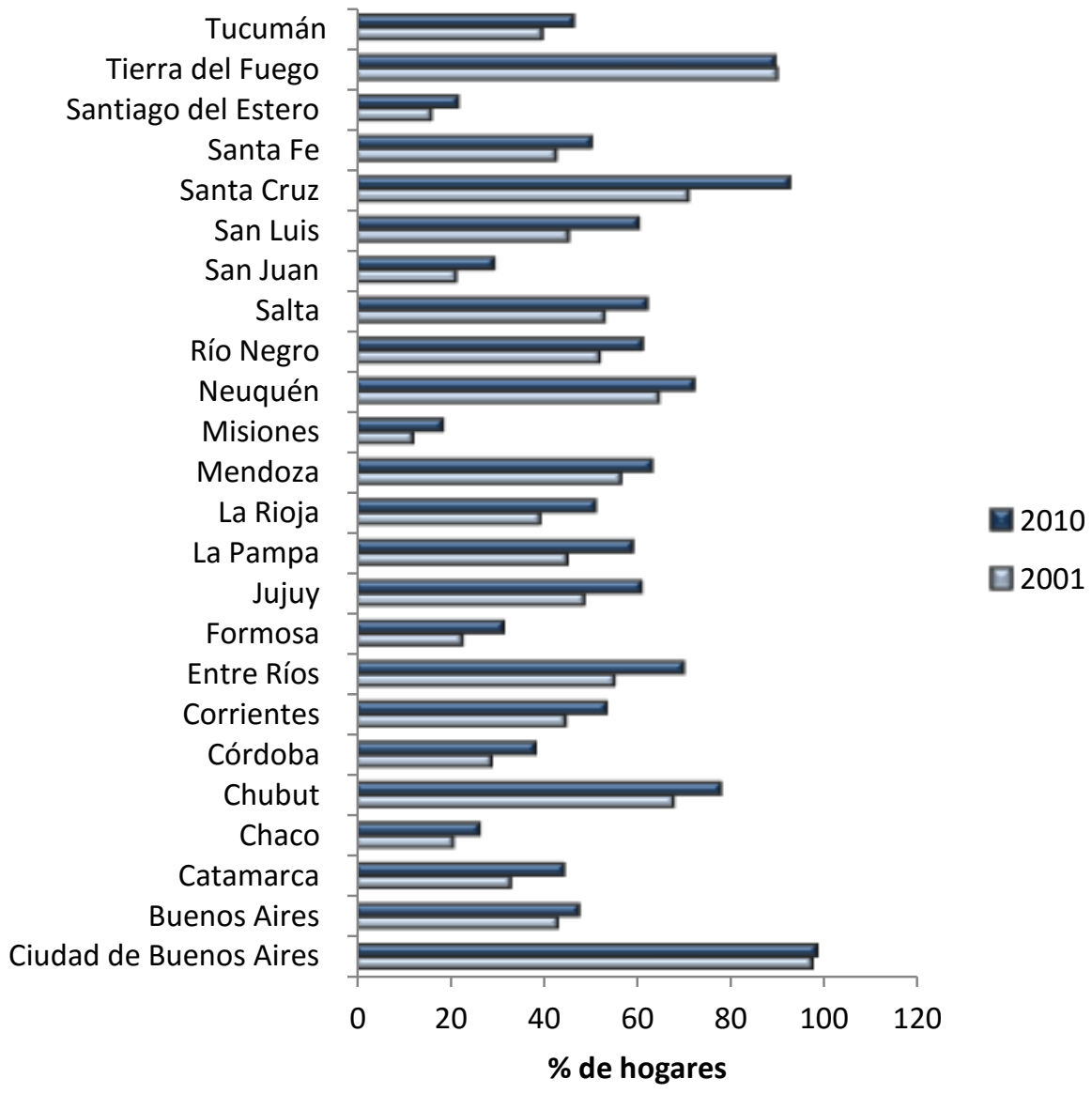

Figura 5. Cobertura de hogares con servicio de cloacas en Argentina (por jurisdicciones) (2001-

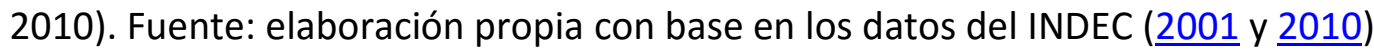

\section{Discusión}

\section{El desafío de la universalización}

En Argentina no hay una ley nacional del agua y saneamiento, en tanto las provincias tienen el dominio de sus recursos naturales y los servicios están descentralizados. La política sectorial ha transitado etapas que van desde la gestión centralizada en la esfera de OSN a la gestión privada y el retorno mayoritario de la gestión pública.

El sector ha heredado agencias regulatorias que fueron constituidas para regular a capitales privados y marcos regulatorios específicos, que más allá de las reestatizaciones, no se han 
modificado estructuralmente y continúan avalando prácticas como el corte de los servicios frente a situaciones de mora de los pagos.

Si bien transitado casi una década y media del nuevo siglo, Argentina se ubica dentro de los países de la región con mayor cobertura de los servicios, aún continúa siendo alarmante el porcentaje de la población que tiene que abastecerse mediante formas menos seguras. En el marco de sociedades capitalistas caracterizadas por "la distribución desigual de los bienes materiales y simbólicos" ( sectores más vulnerables que quedan obligados a comprar en los mercados bienes y servicios "necesarios para la reproducción" (Torrado, 1981). Esta situación refuerza las desigualdades persistentes de la estructura social y acentúa la situación de vulnerabilidad a la que se encuentran expuestos los hogares, principalmente, de menores ingresos.

En la actualidad, el sector experimenta desafíos vinculados a la calidad de la prestación de los servicios en términos de los patrones de la calidad bacteriológica y química del agua y el tratamiento de los efluentes que se recolectan, así como ampliar la presión, y mejorar los niveles de micromedición y macromedición. Asimismo, se requiere aunar los esfuerzos tendientes a sostener una política de inversiones y de incremento de los niveles de eficiencia de las prestatarias a largo plazo que permitan incluir a los sectores que, especialmente en áreas urbanas del país, no logran aún acceder a los servicios.

\section{Referencias}

Aguas Argentinas S.A. (1999). Agua y saneamiento en Buenos Aires (1590-1930). Riqueza y singularidad de un patrimonio. Primera Edición Patrimonio Histórico. Argentina: Aguas Argentinas S.A.

Azpiazu, D. \& Bonofiglio, N. (2006). Nuevos y viejos actores los servicios públicos. Transferencias de capital en los sectores de agua potable y saneamiento y en distribución de energía eléctrica en la post-convertibilidad. Documento de Trabajo № 16, Argentina: Facultad Latinoamericana de Ciencias Sociales. Recuperado dehttp://legacy.flacso.org.ar/uploaded files/Publicaciones/dt nro16 danb oct2006.pdf

Azpiazu, D. \&Forcinito, K. (2004). Historia de un fracaso: la privatización del sistema de agua y saneamiento en el Área Metropolitana de Buenos Aires. En Azpiazu, D., Catenazzi, A. y Forcinito, K. (Eds.), Recursos públicos, negocios privados: Agua potable y saneamiento en el Área Metropolitana de Buenos Aires (pp. 1-112). Argentina: Universidad Nacional de General Sarmiento. Recuperado de http://www.ungs.edu.ar/areas/publicaciones/150/ 
Azpiazu, D., Catenazzi, A. \&Forcinito, K. (2004). Recursos públicos, negocios privados: Agua potable y saneamiento en el Área Metropolitana de Buenos Aires. Argentina: Universidad Nacional de General Sarmiento. Recuperado de http://www.ungs.edu.ar/areas/publicaciones/150/

Azpiazu, D.; Bonofiglio, N. \& Nahón, C. (2008). 18 Agua y energía: Mapa de situación y problemáticas regulatorias de los servicios públicos en el interior del país. Argentina: Facultad Latinoamericana de Ciencias Sociales. Recuperado de http://biblioteca.clacso.edu.ar/gsdl/collect/ar/ar020/index/assoc/D7922.dir/dt18.pdf

Banco Mundial (1996). Argentina. La reforma de los servicios públicos provinciales: dificultades, desafíos y mejores prácticas. Informe confidencial, № 15063-AR, División de Infraestructura, Oficina Regional para América Latina y el Caribe, Estados Unidos: Banco Mundial.

Brunstein, F. (1988).Saneamiento hídrico en el Gran Buenos Aires. Límite de la precariedad. En Brunstein, F. (Ed.), Cuadernos del CEUR 23. Crisis y servicios públicos. Agua y saneamiento en la Región Metropolitana de Buenos Aires (pp. 5-42). Argentina: Centro de Estudios Urbanos y Regionales. Recuperado de http://www.ceurconicet.gov.ar/pdf/cuadernos/cuaderno23.pdf

Catenazzi, A. (2004). Universalidad y privatizaciones de los servicios de saneamiento. El caso de la concesión de Obras Sanitarias de la Nación en la Región Metropolitana de Buenos Aires, 1993-2003. En Azpiazu, D., Catenazzi, A. y Forcinito, K. (Eds.), Recursos públicos, negocios privados: Agua potable y saneamiento en el Área Metropolitana de Buenos Aires (pp. 113-174). Argentina: Universidad Nacional de General Sarmiento. Recuperado de http://www.ungs.edu.ar/areas/publicaciones/150/

Constitución de la Nación Argentina (s. f.). Recuperado de http://infoleg.mecon.gov.ar/infolegInternet/anexos/0-4999/804/norma.htm

Decreto del Poder Ejecutivo Nacional No 1173 de 2004. (2004). Recuperado de http://www.infoleg.gob.ar/infolegInternet/anexos/95000-99999/98364/norma.htm

Decreto del Poder Ejecutivo Nacional $N^{\circ} 214$ de 2002. (2002). Recuperado de http://www.infoleg.gob.ar/infolegInternet/verNorma.do?id=72017

Ferrer, A. (2009). Vivir con lo nuestro. Argentina: Fondo de Cultura Económica. Recuperado de http://www.fondodeculturaeconomica.com/Librerias/Catalogo.aspx?buscar=Vivir+c on+lo+nuestro\&cat=ofefep

112

Verónica L. Cáceres

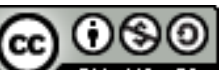

Artículo protegido por licencia Creative Commons 
Ferrer, A. (2008). El capitalismo argentino. Argentina: Fondo de Cultura Económica. Recuperado de https://www.fce.com.ar/ar/libros/detalles.aspx?IDL=744

Hintze, S. (1987). La reproducción de los sectores populares: estrategias y reivindicaciones. Argentina: Facultad de Filosofía y Letras, Universidad de Buenos Aires.

Kosakoff, B. (1988). Desarrollo industrial e inestabilidad macroeconómica. La experiencia argentina reciente. En B. Kosacoff y D. Azpiazu (Eds.), La industria argentina: desarrollo y cambios estructurales (pp. 9-33). Argentina, Buenos Aires: Comisión Económica para América Latina y el Caribe Recuperado de http://repositorio.cepal.org/bitstream/handle/11362/29442/LCbueG103 es.pdf?se quence $=1$

Laurelli, E. (1987). Sistema real de decisiones en la productividad y accesibilidad de servicios de agua y saneamiento. En Brunstein, F. (Ed.), Cuadernos del CEUR, 23. Crisis y servicios públicos. Agua y saneamiento en la Región Metropolitana de Buenos Aires(pp. 4384). Argentina: Centro de Estudios Urbanos y Regionales. Recuperado de http://www.ceur-conicet.gov.ar/pdf/cuadernos/cuaderno23.pdf

Instituto Nacional de Estadísticas y Censos (1981). Censo Nacional de Población y Viviendas de 1981. Argentina: Ministerio de Economía y Finanzas Públicas.

Instituto Nacional de Estadísticas y Censos (1991). Censo Nacional de Población, Hogares y Viviendas de 1991. Argentina: Ministerio de Economía y Finanzas Públicas. Recuperado de https://www.santafe.gov.ar/index.php/web/content/view/full/119432/(subtema)/9 $\underline{3664}$

Instituto Nacional de Estadísticas y Censos (2001). Censo Nacional de Población, Hogares y Viviendas de 2001. Recuperado de http://www.indec.gov.ar/micro sitios/webcenso/censo2001s2/ampliada index.asp ?mode $=01$

Instituto Nacional de Estadísticas y Censos (2010). Censo Nacional de Población, Hogares y Viviendas de 2010. Recuperado de http://www.censo2010.indec.gov.ar/archivos/censo2010 tomo1.pdf

Instituto Nacional de Estadísticas y Censos (2011). Evolución histórica cobertura de viviendas con agua por red. Argentina: Ministerio de Economía y Finanzas Públicas. 
Ley Nacional Consejo Hídrico Federal $\mathrm{N}^{\circ}$ 26.438. Recuperado de http://www.infoleg.gov.ar/infolegInternet/anexos/145000149999/149387/norma.htm

Ley Ente Nacional de Obras Hídricas de Saneamiento $\mathrm{N}^{\circ}$ 24.583. Recuperado de http://www.infoleg.gob.ar/infolegInternet/anexos/30000-34999/30212/norma.htm

Ley de Emergencia Económica y Reforma del Régimen Cambiario $N^{\circ}$ 25.561. Recuperado de http://www.infoleg.gob.ar/infolegInternet/anexos/70000-74999/71477/norma.htm

Ley Nacional de Obras Sanitarias de la Nación. Régimen Legal $N^{\circ} 13.577$. Recuperado de http://www.infoleg.gob.ar/infolegInternet/verNorma.do?id=57202

Ley Nacional de Régimen de Gestión Ambiental de Aguas № 25.688. Recuperado de http://infoleg.mecon.gov.ar/infolegInternet/anexos/8000084999/81032/norma.htm

Ley Nacional de Sociedades cooperativas $\mathrm{N}^{\circ}$ 11.388. Recuperado de http://www.infoleg.gob.ar/infolegInternet/verNorma.do?id=96249

Nahón, C. (2007). La regulación pública de los servicios públicos ¿Quién dijo que todo está perdido? En Basualdo, V. y Forcinito, K. (2007).Transformaciones recientes de la economía argentina. Tendencias y perspectivas (pp. 243-264). Argentina: Prometeo. Recuperado de http://www.prometeoeditorial.com/catalogo/detalle.php?id libro=359,

Ordoque, M. (2007). Servicios de agua potable y alcantarillado en la ciudad de Buenos Aires, Argentina: factores determinantes de la sustentabilidad y el desempeño. Serie Recursos Naturales e Infraestructura, 126, Chile: Comisión Económica para América Latina $y$ el Caribe. Recuperado de http://repositorio.cepal.org/bitstream/handle/11362/6323/S0700405.pdf?sequence=1

OSN (1935). Memorias (1912-1931).Argentina: OSN.

OSN (1966). Panorama del saneamiento urbano de la República Argentina. Argentina: OSN.

Picolotti, J. (2003). The Right to Water in Argentina. Recuperado de http://www.righttowater.info/wp-content/uploads/argentina CS.pdf 
Regalsky, A. (octubre-diciembre, 2010). De Buenos Aires a las provincias. La formación de una gran empresa pública. Obras Sanitarias de la Nación, 1891-1930.Desarrollo Económico, $50 \quad$ (199), $455-482 . \quad$ Recuperado de http://de.ides.org.ar/files/2012/07/199 15821.doc

Rey, O. (2003). El saneamiento en el área metropolitana desde el Virreinato a 1993. Argentina: Aguas Argentinas S.A. Recuperado de http://books.google.co.cr/books/about/El saneamiento en el \%C3\%A1rea metro politana.html?id=y5WftgAACAAJ\&redir esc=y

Saravia, J. (2010). Conclusiones de los Seminarios de Tarifas y Sistemas Tarifarios de AFERAS 2009-2010: Serie de publicaciones sobre tarifas no2. Argentina: Eudecor. Recuperado de $\quad$ http://www.libreroonline.com/argentina/libros/301371/jorge-andressaravia/conclusiones-de-los-seminarios-de-tarifas-y-sistemas-tarifarios-de-aferas2009-2010-serie-de-pub.html

Schifini, J. (1998). Panorama general de las transformaciones en Argentina. Documento Técnico $N^{\circ}$ 5, Argentina: Consejo Federal de Entidades de Servicios Sanitarios.

Tartarini, J. (2007). Obras Sanitarias de la Nación 1912-1950. Origen y apogeo de la primera empresa estatal de saneamiento. Argentina: Aguas y saneamiento Argentino S.A.

Torrado, S. (1981-julio-diciembre). Sobre los conceptos de estrategias familiares de vida y proceso de reproducción de la fuerza de trabajo: notas teórico metodológicas. Revista Demografía y Economía (15), 204-233.

Torres, H. (1993). El mapa social de Buenos Aires. 1940-1990. Serie Difusión № 3.Argentina: Facultad de Arquitectura, Universidad de Buenos Aires. Recuperado de http://www.fadu.uba.ar/publicaciones/cat dif n03.pdf 


\section{Apéndice}

\section{Tabla 1.}

Prestatarias de los servicios de agua y saneamiento en la región metropolitana

\begin{tabular}{cccccc} 
Región & $\begin{array}{c}\text { Juris- } \\
\text { dicción }\end{array}$ & $\begin{array}{c}\text { Prestataria } \\
\text { Principal }\end{array}$ & $\begin{array}{c}\text { Formas jurídicas de } \\
\text { prestación }\end{array}$ & $\begin{array}{c}\text { Organismo de } \\
\text { Regulación y/o Control }\end{array}$ & $\begin{array}{c}\text { Marco } \\
\text { Regulatorio }\end{array}$ \\
$\begin{array}{c}\text { Metropo- } \\
\text { litana }\end{array}$ & Nación & $\begin{array}{c}\text { Agua y } \\
\text { Saneamiento } \\
\text { Argentina (AySA) }\end{array}$ & $\begin{array}{c}\text { Sociedad anónima } \\
\text { con mayoría estatal }\end{array}$ & $\begin{array}{c}\text { Ente Regulador del } \\
\text { Agua y Saneamiento }\end{array}$ & Ley 26.221 \\
\hline
\end{tabular}

Fuente: Elaboración propia en base a Saravia (2010) y Azpiazu, Bonofiglio \& Nahón (2008)

Tabla 2.

Prestatarias de los servicios de agua y saneamiento en la región pampeana

\begin{tabular}{|c|c|c|c|c|c|}
\hline Región & Jurisdicción & $\begin{array}{l}\text { Prestataria } \\
\text { Principal }\end{array}$ & $\begin{array}{l}\text { Formas jurídicas } \\
\text { de prestación }\end{array}$ & $\begin{array}{l}\text { Organismo de } \\
\text { Regulación y/o } \\
\text { Control }\end{array}$ & $\begin{array}{c}\text { Marco } \\
\text { Regulatorio }\end{array}$ \\
\hline \multirow{5}{*}{ Pampeana } & Buenos Aires & $\begin{array}{c}\text { Aguas } \\
\text { Bonaerense } \\
\text { S.A. }\end{array}$ & $\begin{array}{l}\text { Sociedad } \\
\text { anónima con } \\
\text { mayoría estatal }\end{array}$ & $\begin{array}{c}\text { Organismo de Control } \\
\text { del Agua de Buenos } \\
\text { Aires }\end{array}$ & $\begin{array}{l}\text { Decreto } \\
873 / 2003\end{array}$ \\
\hline & La Pampa & $\begin{array}{l}\text { Direcciones } \\
\text { municipales } \\
\text { Cooperativas }\end{array}$ & $\begin{array}{l}\text { Cooperativas y } \\
\text { municipalidad }\end{array}$ & $\begin{array}{c}\text { Administración } \\
\text { provincial del agua } \\
\text { (APA) }\end{array}$ & - \\
\hline & Córdoba & $\begin{array}{l}\text { Aguas } \\
\text { Cordobesas } \\
\text { S.A. }\end{array}$ & $\begin{array}{c}\text { Sociedad } \\
\text { anónima de } \\
\text { capital privado y } \\
\text { cooperativas }\end{array}$ & $\begin{array}{l}\text { Ente Regulador de los } \\
\text { Servicios Públicos }\end{array}$ & Ley $N^{\circ} 8835$ \\
\hline & Entre Ríos & $\begin{array}{c}\text { Obras } \\
\text { Sanitarias de } \\
\text { Entre Ríos } \\
\text { (OSER) }\end{array}$ & $\begin{array}{l}\text { Municipios y } \\
\text { Cooperativas }\end{array}$ & - & - \\
\hline & Santa Fe & $\begin{array}{l}\text { Aguas } \\
\text { Santafesinas } \\
\text { (ASSA) }\end{array}$ & $\begin{array}{l}\text { Sociedad } \\
\text { anónima con } \\
\text { mayoría estatal }\end{array}$ & $\begin{array}{l}\text { Ente regulador de } \\
\text { servicios sanitarios }\end{array}$ & Ley 11.220 \\
\hline
\end{tabular}

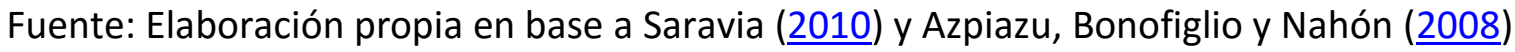


Tabla 3.

Prestatarias de los servicios de agua y saneamiento en la región patagónica

\begin{tabular}{|c|c|c|c|c|c|}
\hline Región & Jurisdicción & $\begin{array}{l}\text { Prestataria } \\
\text { Principal }\end{array}$ & $\begin{array}{l}\text { Formas jurídicas } \\
\text { de prestación }\end{array}$ & $\begin{array}{c}\text { Organismo de } \\
\text { Regulación y/o Control }\end{array}$ & $\begin{array}{c}\text { Marco } \\
\text { Regulatorio }\end{array}$ \\
\hline \multirow[t]{4}{*}{ Cuyo } & & Agua y & & \multirow{4}{*}{$\begin{array}{c}\text { Ente Provincial del } \\
\text { Agua y de } \\
\text { Saneamiento }\end{array}$} & \multirow{4}{*}{$\begin{array}{c}\text { Decreto } N^{\circ} \\
2648 / 10\end{array}$} \\
\hline & Mendoza & $\begin{array}{c}\text { Saneamiento } \\
\text { Mendoza } \\
\text { Sociedad } \\
\text { Anónima (2010) }\end{array}$ & $\begin{array}{l}\text { Sociedad } \\
\text { anónima con } \\
\text { mayoría estatal }\end{array}$ & & \\
\hline & San Luis & $\begin{array}{l}\text { San Luis Agua } \\
\text { Sociedad del } \\
\text { Estado }\end{array}$ & $\begin{array}{l}\text { Sociedad del } \\
\text { estado }\end{array}$ & & \\
\hline & San Juan & $\begin{array}{c}\text { Obras sanitarias } \\
\text { sociedad del } \\
\text { estado }\end{array}$ & $\begin{array}{l}\text { Sociedad } \\
\text { anónima de } \\
\text { capital estatal }\end{array}$ & & \\
\hline
\end{tabular}

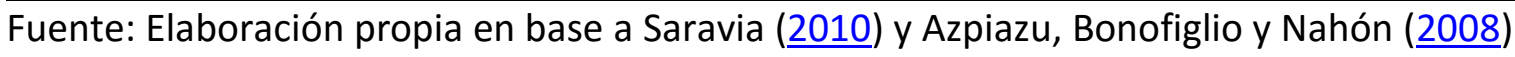

Tabla 4.

Prestatarias de los servicios de agua y saneamiento en la región patagónica

\begin{tabular}{|c|c|c|c|c|c|}
\hline Región & Jurisdicción & $\begin{array}{l}\text { Prestataria } \\
\text { Principal }\end{array}$ & $\begin{array}{l}\text { Formas jurídicas } \\
\text { de prestación }\end{array}$ & $\begin{array}{c}\text { Organismo de } \\
\text { Regulación y/o Control }\end{array}$ & $\begin{array}{c}\text { Marco } \\
\text { Regulatorio }\end{array}$ \\
\hline \multirow{5}{*}{ Patagónica } & Chubut & Cooperativas & $\begin{array}{l}\text { Municipios y } \\
\text { Cooperativas }\end{array}$ & $\begin{array}{c}\text { Ente Provincial de } \\
\text { Agua y Saneamiento }\end{array}$ & \multirow{5}{*}{ Ley 3188} \\
\hline & Neuquén & Cooperativas & Cooperativas & & \\
\hline & Río Negro & $\begin{array}{c}\text { Aguas } \\
\text { Rionegrinas }\end{array}$ & $\begin{array}{l}\text { Sociedad } \\
\text { anónima con } \\
\text { mayoría estatal }\end{array}$ & $\begin{array}{c}\text { Departamento } \\
\text { Provincial del Agua }\end{array}$ & \\
\hline & $\begin{array}{l}\text { Tierra del } \\
\text { Fuego }\end{array}$ & $\begin{array}{l}\text { Municipios y } \\
\text { Cooperativas }\end{array}$ & $\begin{array}{l}\text { Municipios y } \\
\text { Cooperativas }\end{array}$ & $\begin{array}{c}\text { Dirección Provincial de } \\
\text { Obras y Servicios } \\
\text { Sanitarios (Dposs) }\end{array}$ & \\
\hline & Santa Cruz & Cooperativas & Cooperativas & & \\
\hline
\end{tabular}

Fuente: Elaboración propia en base a Saravia (2010) y Azpiazu, Bonofiglio y Nahón (2008) 


\section{Tabla 5.}

Prestatarias de los servicios de agua y saneamiento en la región noroeste

\begin{tabular}{|c|c|c|c|c|c|}
\hline Región & Jurisdicción & $\begin{array}{c}\text { Prestataria } \\
\text { Principal }\end{array}$ & $\begin{array}{l}\text { Formas } \\
\text { jurídicas de } \\
\text { prestación }\end{array}$ & $\begin{array}{l}\text { Organismo de } \\
\text { Regulación y/o } \\
\text { Control }\end{array}$ & $\begin{array}{c}\text { Marco } \\
\text { Regulatorio }\end{array}$ \\
\hline \multirow{6}{*}{ Noroeste } & Catamarca & $\begin{array}{l}\text { Aguas de } \\
\text { Catamarca } \\
\text { S.A.P.E.M }\end{array}$ & $\begin{array}{c}\text { Sociedad } \\
\text { anónima con } \\
\text { mayoría estatal }\end{array}$ & $\begin{array}{l}\text { Ente Regulador de } \\
\text { los Servicios Públicos } \\
\text { y otras concesiones }\end{array}$ & Ley 4836 \\
\hline & Jujuy & $\begin{array}{l}\text { Agua de los } \\
\text { Andes S.A. }\end{array}$ & $\begin{array}{c}\text { Sociedad } \\
\text { anónima mixta } \\
\text { con mayoría } \\
\text { estatal }\end{array}$ & $\begin{array}{l}\text { Dirección de } \\
\text { Servicios Públicos y } \\
\text { otras concesiones }\end{array}$ & \\
\hline & La Rioja & $\begin{array}{l}\text { Aguas de la } \\
\text { Rioja S.A. }\end{array}$ & $\begin{array}{c}\text { Sociedad } \\
\text { anónima de } \\
\text { capital privado }\end{array}$ & $\begin{array}{c}\text { Ente Único de } \\
\text { Control de las } \\
\text { privatizaciones de la } \\
\text { Provincia de La Rioja }\end{array}$ & $\begin{array}{c}\text { Ley } 6.281 \mathrm{de} \\
1996\end{array}$ \\
\hline & Salta & $\begin{array}{l}\text { Aguas del } \\
\text { Norte }\end{array}$ & $\begin{array}{c}\text { Sociedad } \\
\text { anónima con } \\
\text { mayoría estatal }\end{array}$ & $\begin{array}{c}\text { Ente Regulador de } \\
\text { los Servicios Públicos }\end{array}$ & Ley 6835 \\
\hline & $\begin{array}{l}\text { Santiago del } \\
\text { Estero }\end{array}$ & $\begin{array}{c}\text { Aguas de } \\
\text { Santiago S.A. }\end{array}$ & $\begin{array}{c}\text { Sociedad } \\
\text { anónima de } \\
\text { capital privado }\end{array}$ & $\begin{array}{l}\text { Ente Regulador de } \\
\text { los Servicios de } \\
\text { Santiago del Estero }\end{array}$ & Ley 6.225 \\
\hline & Tucumán & $\begin{array}{l}\text { Sociedad } \\
\text { Aguas del } \\
\text { Tucumán }\end{array}$ & $\begin{array}{l}\text { Sociedad } \\
\text { anónima de } \\
\text { capital estatal }\end{array}$ & $\begin{array}{l}\text { Ente Regulador del } \\
\text { Servicio de Agua y } \\
\text { Cloacas de Tucumán }\end{array}$ & $\begin{array}{c}\text { Leyes } 6445 \text { y } \\
6.529\end{array}$ \\
\hline
\end{tabular}


Tabla 6.

Prestatarias de los servicios de agua y saneamiento en la región nordeste

\begin{tabular}{|c|c|c|c|c|c|}
\hline Región & Jurisdicción & $\begin{array}{l}\text { Prestataria } \\
\text { Principal }\end{array}$ & $\begin{array}{l}\text { Formas jurídicas } \\
\text { de prestación }\end{array}$ & $\begin{array}{l}\text { Organismo de } \\
\text { Regulación y/o Control }\end{array}$ & $\begin{array}{c}\text { Marco } \\
\text { Regulatorio }\end{array}$ \\
\hline \multirow[t]{4}{*}{ Nordeste } & Chaco & $\begin{array}{l}\text { Servicio de agua } \\
\text { y mantenimiento } \\
\text { Empresa del } \\
\text { Estado Provincial } \\
\text { Provincia de } \\
\text { Chaco }\end{array}$ & $\begin{array}{l}\text { Empresa Pública } \\
\text { provincial }\end{array}$ & $\begin{array}{l}\text { Administración } \\
\text { Provincial del Agua }\end{array}$ & - \\
\hline & Corrientes & $\begin{array}{l}\text { Aguas de } \\
\text { Corrientes }\end{array}$ & $\begin{array}{c}\text { Sociedad } \\
\text { anónima de } \\
\text { capital privado }\end{array}$ & $\begin{array}{l}\text { Ente Regulador de la } \\
\text { Administración de } \\
\text { Obras Sanitarias } \\
\text { Corrientes }\end{array}$ & $\begin{array}{c}\text { Leyes } 3573 \text { y } \\
3979\end{array}$ \\
\hline & Formosa & $\begin{array}{c}\text { Aguas de } \\
\text { Formosa S.A. }\end{array}$ & $\begin{array}{c}\text { Sociedad } \\
\text { anónima de } \\
\text { capital privado }\end{array}$ & $\begin{array}{c}\text { Ente regulador de } \\
\text { obras y servicios } \\
\text { públicos }\end{array}$ & Ley № 1.142 \\
\hline & Misiones & $\begin{array}{l}\text { Servicio de Aguas } \\
\text { de Misiones S.A. }\end{array}$ & $\begin{array}{c}\text { Sociedad } \\
\text { anónima de } \\
\text { capital privado }\end{array}$ & $\begin{array}{c}\text { Ente Provincial } \\
\text { Regulador de Agua y } \\
\text { Cloacas }\end{array}$ & Ley 3391 \\
\hline
\end{tabular}

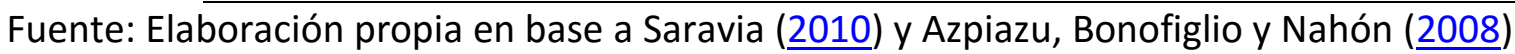

